\title{
Formação de professores de Química no Brasil e no mundo
}

CARMEN FERNANDEZ ${ }^{I}$

\section{Introdução}

$\mathrm{O}$ ENSINO de Ciências, e o de Química em particular, tem atravessado muitas dificuldades no Brasil e no mundo. Das disciplinas escolares, a Química é aquela usualmente considerada a mais impopular, difícil e abstrata, e boa parte dos conceitos químicos aprendidos na escola não faz sentido para um número significativo de estudantes. Por outro lado, o conhecimento de Química num país é a base para a inovação, a alfabetização científica e a melhor saída para a solução de problemas em conexão com o desenvolvimento sustentável (Risch, 2010)

Nesse sentido, se faz importante refletir sobre a formação de professores de Química, pois são eles, em última instância, os responsáveis por ensinar esse conhecimento. Tal formação se faz de modos diferentes em distintos países. Dentre os vários trabalhos que tratam da temática da formação de professores, um livro em particular apresenta capítulos relacionados a diversas nações, totalizando 25 países nos diferentes continentes, abordando a estrutura curricular, as questões de investimento, como ocorre o ensino de Química nos diferentes níveis e como se dá a formação de professores de Química (Risch, 2010). Outro livro que complementa o primeiro trata especificamente da formação de professores em geral ao redor do mundo, abordando oito países (Darling-Hammond; Lieberman, 2012). Tomando por base principalmente esses dois textos e complementando com vários outros foi realizada uma compilação de informações relevantes à formação dos professores de Química e serão analisadas semelhanças e diferenças nos distintos contextos.

\section{A relevância dos professores}

De maneira geral e nos discursos, os professores quase sempre são reconhecidos em todos os lugares do mundo como sujeitos relevantes para o sucesso de uma nação. Na prática, porém, nem sempre esse reconhecimento se traduz em valorização social e/ou econômica.

$\mathrm{Na}$ história da humanidade, o processo da educação não se deu como o conhecemos hoje em dia em salas de aulas, dentro de escolas e com um professor no comando. Assim, 
[...] o processo de educação, tal como se conhece hoje em dia, realizado formalmente nas escolas é relativamente recente na nossa sociedade. Nos povos primitivos a educação dos novos membros da comunidade acontecia como socialização direta, mediante a participação das crianças nas atividades da vida adulta. Esse processo, entretanto, deixou de ser eficiente com o desenvolvimento histórico das comunidades humanas e outras formas de socialização secundária passaram a existir que terminou por conduzir aos sistemas de escolarização obrigatória para todas as camadas da população. (Pérez Gómez, 2000, p.13)

Por outro lado, e por conta de demandas da sociedade, a função educativa da escola é imersa numa tensão entre reprodução e mudança pois:

[...] a escola deve provocar o desenvolvimento de conhecimentos, ideias, atitudes e pautas de comportamento que permitam sua incorporação eficaz no mundo civil, no âmbito da liberdade de consumo, da liberdade de escolha e participação política, da liberdade e responsabilidade na esfera da vida familiar. Características bem diferentes daquelas que requer sua incorporação submissa e disciplinada, para a maioria, no mundo do trabalho assalariado. (Pérez Gómez, 2000, p.15)

No processo de socialização e por conta dessa função dialética que ocorre nas escolas, o professor é considerado o elemento crucial. No Brasil, entretanto, até os dias atuais, essa profissão não conseguiu ainda atingir o mesmo status das demais. O salário médio dos professores da Educação Básica é em torno de 60\% dos salários de outros profissionais com igual escolaridade. Houve, nos últimos anos, uma expansão muito grande no número de alunos na escola sem a necessária formação de professores, o que provocou uma série de improvisações, resultando num ensino de baixa qualidade. Além disso, não há consenso sobre a existência de um corpo de conhecimentos que defina a profissão de professor. Ainda há muita controvérsia em como esse profissional deve ser formado e quais os conhecimentos base que definem alguém como professor. Soma-se a isso o fato que a profissão professor tem que acompanhar as mudanças da sociedade e do conhecimento que não são poucas. Como exemplo dessa falta de profissionalização, na Educação Infantil (antigo Ensino Primário) a professora polivalente brasileira ainda muitas vezes é chamada de "tia" e acaba por exercer um papel mais maternal do que profissional (Masetto, 1998). Por outro lado, no Ensino Médio e no Superior, a ideia difundida é que para ser professor basta saber algum conteúdo (Kind, 2009). Em nenhum dos casos parece se exigir um profissionalismo semelhante àquele exigido para o exercício de qualquer outra profissão (Masetto, 1998).

Nesse contexto, a formação de professores de Química assume um papel relevante no processo de ensino e aprendizagem. Quando se está em sala de aula tem-se a impressão de que a Química é ensinada da mesma forma em qualquer parte do mundo. Mas, de fato, há muitas diferenças entre os países. Na Europa há, de forma geral, duas abordagens para a formação de professores: a consecu- 
tiva, onde o estudante primeiro faz as disciplinas de uma determinada área (por exemplo, química) e, na sequência, faz disciplinas pedagógicas, ou a concorrente, onde os estudos pedagógicos e a preparação para ensinar são realizados em conjunto com as disciplinas de conteúdo específico. Entretanto, a situação é bastante complexa e há de fato algo como vinte modelos diferentes de formação de professores atualmente em uso em toda a Europa. Por exemplo, professores de química são formados em faculdades de educação em algumas universidades e em faculdades ou institutos científicos em outras. (Maciejovska; Byers, 2015). No Brasil, em particular, há muitos problemas educacionais a serem enfrentados e a formação dos professores é uma parte crucial dessa história. Historicamente a formação se dava num currículo que ficou conhecido como $3+1$ que se constituía em três partes do curso de disciplinas de conteúdo específico (no caso, químicas) e uma parte em disciplinas pedagógicas. Seria o equivalente à abordagem consecutiva europeia.

Assim, este artigo aborda o ensino de Química em alguns países e trata mais especificamente da formação de professores de Química nesses países. Foram selecionados seis países, além do Brasil, para abordar o tema. São eles: Alemanha, Austrália, Canadá, Estados Unidos, Finlândia e Índia. A escolha desses se deu primeiramente por uma limitação de espaço, mas tentando atender alguns critérios, a saber: países que tivessem uma dimensão territorial expressiva e uma diversidade cultural para que se pudesse ter uma relativa aproximação com a complexa realidade brasileira. A exceção foi feita à Finlândia e à Alemanha. A primeira foi escolhida pois apresenta uma educação almejada por todos, e a segunda, por ser uma das grandes potências econômicas mundiais. Deixaram-se de fora, assim, os denominados Tigres Asiáticos, embora tenham um desempenho educacional excepcional, pois são sistemas educacionais que contam com um número muito menor de estudantes que o sistema brasileiro. Os países são apresentados em ordem alfabética deixando o Brasil por último.

\section{Alemanha}

\section{Panorama geval da educação na Alemanba}

A Alemanha é uma república federativa e compreende 16 estados. Cada um é responsável pelo seu sistema escolar, mas existe um currículo básico que deve ser seguido por todos os estados. De forma geral, as aulas vão das 7 h 45 às 13 h00 e cada aula tem duração de 45 minutos. Ultimamente várias escolas têm estendido esse período para as tardes aumentando o número de escolas integrais.

A pré-escola vai dos 3 aos 5 anos de idade e não possui um currículo obrigatório. O nível primário vai dos 6 aos 10 anos de idade (níveis 1 a 4). Depois do primário os alunos fazem o nível secundário I e a partir daí há quatro diferentes percursos educacionais: Hauptschule, Realschule, Gesamtschule (todos esses possuindo níveis 5 a 10) ou Gymnasium (níveis 5 a 9). Houve uma grande reforma educacional nos últimos anos e o estado deixou de prescrever os fundamentos do currículo de modo a deixar explícitos conteúdos e temas aos professores e 
também enxugar os quatro percursos para somente dois - Gymnasium e Gesamtschule. Atualmente o objetivo é desenvolver um currículo orientado por competências. Mais especificamente, o ensino da Química se inicia no nível 7, sendo disciplina obrigatória e é ensinada duas vezes por semana em aulas de 45 minutos. O nível secundário I se completa com 9 anos totais no caso do Gymnasium ou 10 anos totais no caso do Gesamtschule. Para os estudantes que seguiram pelo Gymnasium no nível secundário I não há obrigação de seguir pelo secundário II. Para aqueles que seguem uma trajetória profissional há dois caminhos possíveis: um estudo vocacional junto com o trabalho ou uma escola vocacional. Por outro lado, aqueles que vão para a Universidade precisam seguir pelo Gesamtschule e realizar ao final o Abitur que é um exame escrito e oral onde as competências adquiridas são testadas e difere de estado para estado (Risch, 2010).

Esses diferentes caminhos não são opcionais, os estudantes são encaminhados para uma ou outra rota de acordo com suas competências definidas pelos seus professores ao final da escola primária ( 9 anos de idade). Há muitas críticas ao sistema que é considerado socialmente injusto e altamente seletivo. Essa divisão rígida dos estudantes em tenra idade influencia as chances de cada um em termos de educação e chances de emprego. Estudos mostram que esse sistema é particularmente prejudicial para pessoas com um menor nível socioeconômico, especialmente aos filhos de imigrantes. Por outro lado, é esse sistema educacional eficiente que faz da Alemanha uma das maiores economias do mundo e uma das democracias mais estáveis (Risch, 2010).

\section{Formação de professores de Química na Alemanba}

A formação de professores na Alemanha é uma preocupação de estado e, assim, cada estado tem suas próprias regras. A formação inclui o estudo em duas áreas específicas na universidade, ou seja, os professores são formados para atuar em duas disciplinas na escola. Além dos conteúdos específicos, o curso compreende disciplinas de teorias da especialidade e da ciência da educação em geral. As disciplinas específicas de conteúdo na licenciatura são diferentes das disciplinas do bacharelado. As disciplinas químicas na licenciatura preparam especificamente os alunos para se formarem professores e diferem de acordo com a Universidade. O contato com os alunos reais nas escolas é feito por um período de dois anos durante os estágios supervisionados (Risch, 2010).

Existem em torno de 50 universidades na Alemanha que possuem professores especialistas na área de didática da Química e que atuam na formação de professores. Os licenciandos (Bachelors' Chemistry Teacher Education) necessitam escrever uma monografia (Bachelors' thesis) e uma dissertação de mestrado relacionada ao ensino de algum conteúdo químico. A formação termina com um Exame Nacional. Aqueles que completam o programa são então treinados como professores para o tipo de escola que irão lecionar. Professor na Alemanha é uma profissão valorizada socialmente e há um investimento grande do sujeito que quer se tornar professor. Em geral são bons alunos que seguem por esse caminho. 


\section{Austrália}

\section{Panorama geval da educação na Austrália}

A Austrália compreende seis estados e dois territórios e a educação é obrigatória entre 6 e 16 anos de idade (ano 1 a 10) e compreende 13 anos com pequenas variações entre os estados. A estrutura básica do sistema educacional compreende um período preparatório de 1 a 2 anos anterior ao ano 1 que não é obrigatório, mas quase que universalmente feito; o nível primário - anos 1-6 ou 1-7 e nível secundário - anos 7-12 ou 8-12, dependendo do estado. Depois há um exame para entrada na Universidade. $\mathrm{O}$ ano letivo compreende quatro termos, cada um de dez semanas e separados por algumas pausas sendo a mais longa de dezembro a janeiro durante o verão australiano (Treagust; Chandrasegaran, 2010).

\section{Formação de professores de Quimica na Austrália}

A maioria dos estados e territórios exige, pelo menos, quatro anos de curso universitário para formar professores para a escola primária e secundária. Os programas de formação de professores se constituem de estudos profissionais (conhecimento teórico e habilidades), estudos curriculares (conhecimento específico da disciplina e habilidades pedagógicas, e experiência profissional supervisionada por 12 a 20 semanas. Para professores de Química em nível secundário os programas fornecem uma integração de estudos profissionais e curriculares em uma ou duas disciplinas, uma das quais Química. Existem programas diferentes em várias universidades na Austrália. Os professores de Química em nível secundário geralmente obtêm um diploma de Bacharelado em Educação com especialização em Química. Por exemplo, no curso de quatro anos da Universidade de Curtin, os futuros professores estudam Química durante os três primeiros anos e pelo menos mais uma outra ciência ou matemática. No terceiro ano os estudantes são selecionados para o programa de honras (que inclui um projeto de pesquisa) ou podem continuar com o curso padrão de formação de professores.

\section{Canadá}

\section{Panorama geval da educação no Canadá}

O Canadá teve uma ampla reforma educacional no início na década de 1990. As mudanças ocorreram nos quadros administrativos escolares que se fundiram para melhorar a eficiência, na criação de conselhos escolares visando maior envolvimento dos pais, no melhor controle dos gastos com educação, entre outras (Silva, 2015). O Canadá passou por processo similar ao do Brasil, em relação à expansão da educação. A ampliação de oferta de matrículas não acompanhou a qualidade requerida.

De um modo geral, o sistema de ensino canadense é organizado em quatro níveis, a saber: pré-elementar, elementar, secundário e pós-secundário (ou universitário). No Canadá, cada província tem departamentos ou ministérios de educação os quais são os responsáveis pela organização, provisão e avaliação da educação nos níveis elementar e secundário. Um aspecto que não se pode 
deixar de enfatizar é que o Canadá apresenta uma grande diversidade cultural e os sistemas de ensino preocuparam-se bastante com esse aspecto na reforma objetivando unir diferentes elementos históricos, geográficos e étnicos. Em 1988, foi criada a Lei do Multiculturalismo consagrando dois princípios essenciais: liberdade de conservação e compartilhamento do patrimônio cultural para todas as pessoas da sociedade canadense, e a criação de políticas, programas e práticas que garantam oportunidades iguais focando o entendimento e o respeito pela diversidade da sociedade canadense (Silva, 2015).

Descreve-se aqui o processo de mudança que teve a abordagem educacional adotada em Ontário, Canadá, que desde 2003 tem resultado numa melhora significativa nos estudantes. A educação em Ontário apresenta grandes desafios - grandes áreas urbanas, e áreas rurais remotas; níveis de pobreza significativas nas áreas rurais e urbanas; grande diversidade na população e muitos estudantes que tem o Inglês como segundo idioma; entre outros (Levin, 2012).

As mudanças em Ontário foram sistematicamente planejadas, como o monitoramento do desempenho dos alunos, da qualidade da escola e das competências dos professores em relação aos padrões profissionais. Assim, Ontário foi reconhecida pela sua experiência educacional bem-sucedida aliada à excelência técnica e à competência de seus docentes.

Até 2003 o sistema educacional em Ontário se mostrava bastante caótico. De 1995 até 2003 o governo acusava os professores de serem preguiçosos, impunha um teste de múltipla escolha para certificação dos professores, cortava financiamento de escolas, removia alguns privilégios e impunha um novo currículo, todas mudanças muito rápidas. As avaliações dos estudantes mostravam estagnação ou diminuição no caso do número de formados na escola secundária. A moral nas escolas era baixa e as greves muito frequentes. O número de professores que abandonava a profissão era grande e muitos alunos trocavam as escolas públicas pelas privadas. Em 2003 foi eleito um novo governo que fez da reconstrução da educação pública a sua maior prioridade. $\mathrm{O}$ novo primeiro ministro da Educação de Ontário veio imbuído de um forte compromisso de reconstruir uma relação positiva com a profissão de professor como um elemento chave para o sucesso dos estudantes. Em 2007 a educação em Ontário estava numa situação muito diferente. Todos os resultados de avaliações de estudantes melhoraram, os atritos com os professores diminuíram dramaticamente e o crescimento de matrículas em escolas particulares estacionou. Esses resultados não foram consequência de uma única ação. Em Ontário eles foram devidos a alguns elementos chave: liderança política forte e positiva do primeiro ministro da Educação através de financiamento, legislação e outros suportes; agenda clara com objetivos simples mas poderosos que promoveram engajamento do público e da profissão; forte engajamento positivo do setor da educação para construir a sua identidade e compromisso com a estratégia e um foco central na capacidade de construção, aumentando a capacidade das pessoas em atingir bons resulta- 
dos (Levin, 2012). De modo geral, o processo de mudança de Ontario focou em poucos objetivos-chave. A abordagem foi respeitosa com os conhecimentos profissionais dos professores e com a prática desses.

\section{Formação de professores de Química no Canadá}

No final dos anos 1980, Canadá e Estados Unidos começaram um movimento de reforma na formação inicial de professores da educação básica que tinha por objetivo a valorização profissional dos professores. Essa ideia partiu dos trabalhos de Shulman $(1986,1987)$ que defende o princípio de que existe uma base de conhecimento para o ensino, com o intuito de melhorar a formação dos professores. Dentre esses conhecimentos destaca-se o Conhecimento Pedagógico do Conteúdo (PCK, Pedagogical Content Knowledge) que é considerado o conhecimento profissional específico dos professores. O PCK é o conhecimento que distingue um professor de Química de um químico (Fernandez, 2014a). Nessa época iniciou-se um processo de profissionalização que favoreceu a legitimidade da profissão, distinto do entendimento da docência como uma vocação ou ainda missão. Nos últimos anos, aspectos relevantes têm contribuído para aumentar o status dos professores para o fortalecimento profissional. Dentre esses podemos citar: admissão seletiva à capacitação docente, desenvolvimento de padrões profissionais de ensino, supervisão mais rigorosa - em alguns casos, pelas autoridades escolares - e tempo adicional para capacitação em serviço.

Diretores de escolas e superintendentes devem possuir qualificações específicas em Ontário. Essas, assim como as qualificações dos professores, são controladas por lei pela Faculdade de Educação de Ontario (Ontario College of Teachers, OCT), que é governada por um conselho próprio, formado por professores. Assim, para lecionar em Ontário, um professor formado nessa província ou em outra precisa se tornar membro do Ontario College of Teachers. A inscrição no OCT é o requisito necessário para lecionar em escolas financiadas por fundos públicos em Ontário. Os professores que trabalham nas escolas públicas de Ontário devem ser membros do OCT e possuir um Certificado de Qualificação e Registro ou um Certificado de Transição de Qualificação e Registro emitido pelo OCT. Esses certificados são licenças para ensinar nas escolas públicas de ensino fundamental e médio do Ontário (OCT, 2018).

O certificado de um professor descreve as disciplinas que ele está qualificado para ensinar. Para se tornar um professor em Ontário, os candidatos devem concluir um curso de pós-graduação e concluir um programa inicial de formação de professores oferecido por uma faculdade de educação credenciada. A faculdade credencia programas de formação inicial de professores (por vezes referidos como programas de pré-serviço) oferecidos em Ontário e revê programas para garantir que os requisitos de acreditação sejam mantidos (OCT, 2018). A partir de 2015, o programa inicial de formação de professores nas faculdades de educação de Ontário foi expandido para quatro semestres e inclui o dobro do tempo de prática de ensino ( 80 dias, ao invés e 40 ). 
Assim, a formação de professores em Ontário é bastante regulada. O Ontario College of Teachers licencia, regulamenta e regula a profissão docente de Ontário no interesse público. Professores que trabalham em escolas públicas em Ontário devem ser certificados para ensinar na província e serem membros do OCT. Esse órgão estabelece padrões éticos de prática, emite certificados de ensino e pode suspendê-los ou revogá-los, credencia programas e cursos de formação de professores e investiga se houve reclamações sobre os membros. Sua atuação é semelhante aos Conselhos Regionais que regulamentam diversas profissões no Brasil.

\section{Estados Unidos}

\section{Panorama geval da educação nos Estados Unidos}

Os Estados Unidos compreendem 50 estados e comportam um dos maiores sistemas educacionais do mundo. Cada estado é responsável pela sua educação pública e tal responsabilidade é geralmente delegada aos distritos e escolas. A educação é obrigatória por dez anos e se inicia aos 4-5 anos de idade e se completa aos 15-18 anos de idade. Essas idades variam de acordo com os estados. A estrutura do dia escolar é tão diversa quanto o número de distritos. Em geral o ensino médio começa mais cedo - em torno de $7 \mathrm{~h} 30$ - do que o ensino fundamental ou primário. Como as escolas públicas em distritos suburbanos e rurais fornecem transporte público, os alunos mais velhos são transportados mais cedo. $\mathrm{O}$ dia escolar termina por volta das $14 \mathrm{~h} 30$ para os mais velhos e às 15 h00 para os mais novos. O sistema educacional inclui as creches (de 3 a 5 anos), a educação primária (de 6 a 13 anos) e a educação secundária (de 14 a 17 anos). Não há um currículo nacional, mas os esforços da reforma em educação em ciências produziram dois documentos. O primeiro, National Science Education Standards, estabelece padrões para conteúdo, ensino, avaliações, desenvolvimento profissional, programas e sistemas. Esses padrões, entretanto, não são obrigatórios. O segundo, American Association for the Advancement of Science (AAAS), representa a maior organização de cientistas e engenheiros do mundo e publicou o Projeto 2061: Ciência para todos os americanos que estabelece o que uma pessoa alfabetizada cientificamente deve possuir (Scantlebury, 2010).

Muitas escolas secundárias nos Estados Unidos são ditas "abrangentes" pois oferecem todas as disciplinas. Existem também as escolas que tem um foco específico como ciências e matemática ou artes. E ainda existem as escolas técnicas profissionalizantes em alguns estados. Uma porcentagem pequena de estudantes frequenta as escolas com foco em ciências mas existe uma grande variedade de requerimentos necessários ao estudo de ciências no país. Assim é impossível dizer qual currículo de Química um estudante do ensino médio possui.

\section{Formação de professores de Química nos Estados Unidos}

A formação de professores de Química é feita nas Universidades. Mas são os Conselhos Estaduais de Educação que certificam as pessoas para ensinar. A legislação prevê que as crianças devam ser ensinadas por professores altamente 
qualificados. Isso significa professores com grau de bacharelado, certificação do estado ou licenciatura e tem de provar que conhecem cada disciplina que ensinam. Em escolas rurais ou urbanas o professor pode ser muito bem qualificado para ensinar uma disciplina, mas será designado para ensinar uma segunda disciplina na qual ele não seja tão qualificado. Muitos estados usam nessas ocasiões um teste de conteúdo desenvolvido pelo Serviço de Testes Educacionais conhecido como PRAXIS II para testar o conhecimento especializado de professores de seus tópicos. Por exemplo, se um professor de Biologia passa no PRAXIS II de Química, então ele pode ser considerado altamente especializado em Química também. Entretanto, há discrepâncias entre os resultados oficiais dos professores nesse Teste Educacional e as autoavaliações dos professores. Muitos professores não se consideram altamente especializados em disciplinas das quais eles passaram no PRAXIS II. Pode ocorrer também que em algumas escolas rurais não haja um interesse muito grande dos estudantes em aprender Química e então não se contrata um professor altamente qualificado, mas sim um professor de outra disciplina. Como resposta à obrigação de contratar professores altamente qualificados, os estados têm usado uma série de estratégias para certificar professores. Esses programas de rotas alternativas de certificação reduzem a ênfase no potencial dos professores aprenderem pedagogia e/ou conhecimento pedagógico do conteúdo. A maneira de formar professores de Química nos Estados Unidos é muito diversa. Alguns programas são alocados nas Faculdades de Educação enquanto outros residem nos Departamentos de Química nas Universidades. A tendência, entretanto, é que o professor possua uma graduação em Química e então entre na profissão de professor através de um programa alternativo de certificação ou ainda, realize uma pós-graduação para atingir o conhecimento do conteúdo e apresente experiência necessária para uma certificação (Scantlebury, 2010).

\section{Finlândia}

\section{Panorama geval da educação na Finlândia}

A Finlândia implementou uma reforma na educação nas décadas de 1970 a 1990 e teve como princípio oferecer oportunidades iguais aos seus estudantes e proporcionar aprendizagem ao longo de toda a vida. Segundo Silva (2015), no período de 1999 a 2003 o sistema educacional finlandês investiu em idiomas estrangeiros, avaliações em busca de melhor qualidade na educação, aprimoramento da cooperação entre as escolas e o mundo do trabalho, e estabeleceram-se padrões para capacitação de professores pré-serviço e em-serviço. Em 2003, um Conselho de Avaliação foi criado, em nível nacional, com objetivo de coordenar procedimentos de verificação e avaliação.

O Sistema Educacional na Finlândia compreende nove anos de escolarização básica para todas as crianças a partir de 6 anos, três anos de educação secundária (pode ser geral ou profissionalizante) e educação superior. Antes dos seis anos há pré-escolas não obrigatórias (Lampiselkä, 2010). O ano letivo é com- 
posto de 190 dias e a taxa de evasão é uma das menores no mundo, 99,7\% das crianças completam a escolarização. O governo, autoridades locais e outras entidades financiam a escola básica (graus 1 a 9) que é gratuita para os estudantes. O financiamento inclui livros, suprimentos, transporte, pelo menos uma refeição quente, atendimento médico e dentário. O ensino médio e o superior também são gratuitos, mas nesses níveis os alunos têm de comprar os próprios livros e computadores. Em geral os alunos selecionam as escolas pela proximidade do local de onde moram, mas algumas escolas apresentam uma maior popularidade e realizam testes de seleção de estudantes. Até os anos 1990 o currículo nas escolas era centralizado e o governo definia o que seria trabalhado nas escolas. Para tanto, o Conselho Nacional de Educação fiscalizava os conteúdos dos livros e os inspetores de matemática e ciências visitavam as escolas e monitoravam as aulas. Depois dessa data, houve uma mudança radical na administração escolar nacional e o currículo passou a ser descentralizado. A partir daí a participação dos professores na preparação dos currículos foi condição central para as mudanças das atividades nas escolas. O Conselho Nacional de Educação passou a fornecer apenas algumas orientações para o currículo e a responsabilidade passou a ser de cada escola de escrever seu próprio currículo com envolvimento dos professores, das famílias e dos alunos. A consequência prática foi que a reforma enfatizou a profissionalização dos professores.

\section{Formação de professores de Química na Finlândia}

O grande segredo do sucesso da educação na Finlândia é a qualidade de seus professores. A profissão de professor é muito intimamente ligada à cultura finlandesa. Historicamente a Finlândia brigou por manter sua identidade nacional, sua língua materna e seus valores primeiro durante quatro séculos sob o domínio da Suécia, depois mais de um século sob domínio do império russo, e depois um outro século como uma nação independente (Sahlberg, 2012). Mas educação sempre foi parte integral da sociedade finlandesa. Ainda no século XVII a alfabetização era responsabilidade dos padres e outros religiosos e se exigia dos casais que quisessem se casar pela Igreja que soubessem ler e escrever. Depois os professores foram gradualmente assumindo essa responsabilidade no sistema público de educação e exerceram um papel preponderante na manutenção da identidade finlandesa durante os domínios sueco e russo. Até 1960 o nível educacional na Finlândia era comparável à Malásia e ao Peru e estava muito atrás de seus vizinhos escandinavos.

Os professores gozam de grande respeito e confiança da sociedade finlandesa. A profissão de professor na Finlândia está entre as mais admiradas e desejadas e possui status semelhante ao de médico e advogado. Para ser professor primário na Finlândia, os candidatos precisam atingir notas altas, ter personalidade positiva e excelentes habilidades interpessoais. Hoje em dia somente um em cada dez candidatos é aceito para se preparar para se tornar um professor nas escolas primárias finlandesas. 
A formação de professores é feita nas Universidades (para professores da educação pré-primária, primária e da educação secundária) e em faculdades vocacionais (politécnicas) para professores de disciplinas profissionais. Os professores para nível primário precisam ter mestrado em educação. A especialização como professor requer passar num teste de aptidão. $\mathrm{O}$ tempo médio para completar a formação é cinco anos. A formação de professores para o nível secundário (por exemplo, de Química) se dá na Universidade nos Institutos disciplinares e em nível de mestrado na disciplina que irão lecionar. Além disso, eles têm de cursar outras disciplinas para além da área de especialização (por exemplo, física) e disciplinas pedagógicas nos Departamentos de Formação de Professores. Nos níveis de 1 a 6 os professores são polivalentes, ensinando todas as disciplinas. Professores especialistas lecionam nos níveis 7 a 9 e no nível secundário e eles normalmente ensinam uma ou duas disciplinas. Exceção é feita aos professores de Matemática, Física e Química que ensinam as três disciplinas, além de ensinar também tecnologias da informação como uma disciplina optativa (Lampiselkä, 2010).

O programa de formação de professores de Química compreende disciplinas avançadas de Química dentro do curso principal (major studies), estudos de temas no curso menor (minor studies) e estudos básicos no outro. Assim que uma disciplina de estudo é escolhida, o licenciando precisa escolher os estudos pedagógicos para professores como tema menor (minor subjects). A primeira parte do mestrado no Departamento de Química fornece a base científica para estudos posteriores. Perto do final do curso o estudante escolhe se quer se especializar em Química analítica, inorgânica, orgânica, físico-química ou ainda educação química. A graduação se encerra com uma dissertação de mestrado no campo selecionado. As disciplinas de didática química são distribuídas durante o curso. O Departamento de Química fornece seis cursos de Química pedagogicamente orientados em nível avançado: Química como Ciência e como Disciplina; Modelos e Visualização em Química; Áreas Centrais da Educação Química l e 2; e Trabalho Prático em Educação Química 1 e 2. Em geral a dissertação de mestrado apresenta uma orientação didática. Os estudos durante a formação de professores possuem uma abordagem baseada no Conhecimento Pedagógico do Conteúdo (PCK) que é o conhecimento necessário para a profissão professor (Shulman, 1986, 1987; Kind, 2009; Fernandez, 2014a, 2014b, 2015).

A formação prática ocorre em escolas especiais para formação de professores que pertencem a faculdades dentro das universidades (denominadas escolas normais) embora sejam administrativamente independentes e os licenciandos são supervisionados por professores que tenham no mínimo mestrado e dois anos de experiência. Os licenciandos participam de um a dois períodos de estágios. Nesses treinamentos práticos os alunos percorrem as etapas de estudos curriculares e intencionalidades como base para o processo de ensino, planejamento, implementação, avaliação e reflexão, assim como desenvolvem habilidades para justificar e explicar suas próprias decisões pedagógicas entendendo a efetividade 
e adequação de métodos de ensino diferentes para situações de aprendizagem particulares (Lampiselkä, 2010).

\section{Índia}

\section{Panorama geval da educação na Índia}

A Índia é um estado federativo consistindo de 35 estados. Há aproximadamente 29 línguas oficiais no país. Existem muitos sistemas formais que governam e guiam a educação na Índia - em nível nacional, estadual, escolar e em escolas internacionais. $\mathrm{O}$ calendário escolar vai de abril a março. A escola começa às $7 \mathrm{~h} 45$ e termina às $14 \mathrm{~h} 00$ com aulas de 35 a 40 minutos. A estrutura do sistema educacional compreende os níveis elementar (de 2 a 5 anos), primário ( 6 a 10 anos), primário superior ( 11 a 13 anos), secundário (14-15 anos) secundário superior (16-17 anos). A evasão dos alunos é alta. Aproximadamente $30 \%$ dos alunos abandonam a escola ainda no nível primário e em torno de $17 \%$ evadem na transição para o primário superior. Somente entre 15\%-20\% dos estudantes atingem o secundário superior devido ao status socioeconômico ruim (Baxi, 2010).

Há muitos sistemas formais que governam e orientam a educação na Índia. Entre eles, o Conselho Central de Educação Secundária que governa as escolas em nível nacional; o Conselho Estadual; o Conselho para o Exame de Certificado de Escolas Indianas que governa as escolas afiliadas e o Programa Internacional de Bacharelado que orienta as escolas internacionais.

A educação química na Índia não tem sido especialmente boa. Apenas um pouco de Química é encontrada no sistema educacional indiano como parte dos cursos de ciências gerais durante os primeiros oito anos de escolaridade. No nível primário a escola é dividida em cinco graus denominados classe 1 a 5 . De 1 a 3 os alunos estudam Hindi, Inglês, Matemática, Conhecimentos Gerais e Ciências do dia a dia. Há cinco aulas por semana de Ciências do dia a dia. Nas classes 4 e 5 a disciplina Ciências do dia a dia é dividida em duas: uma mais focada para as Ciências e outra para os Estudos Sociais e há quatro aulas de cada. No primário superior há cinco aulas de Ciências por semana e, durante esses anos a Ciência emerge como uma disciplina separada com complexidade aumentada rapidamente. Até a classe 5 há um predomínio da Biologia que depois é dividida entre Física, Química e Biologia. Em Química os tópicos incluem separação de misturas, ácidos, bases e sais, metais e não metais. No nível secundário há um grande salto das classes 9 para a 10 . Na classe 10 os alunos se preparam para o primeiro exame regulamentado (Baxi, 2010).

Nos $9^{\circ}$ e $10^{\circ}$ anos de escola, a Química é ensinada como uma disciplina separada, e nos dois anos seguintes seu estudo é opcional. Além disso, os estudantes aparentemente não consideram a Química uma opção atraente e os números diminuem significativamente em todas as etapas educacionais (Sait, 2015).

\section{Formação de professores de Química na Índia e desafios}

Ciência não é um tópico atraente para os estudantes indianos. A infraestrutrura nas escolas é um grande desafio em termos de coisas básicas como 
água potável e playground, mas também em termos de materiais curriculares para os professores. O estado dos laboratórios deixa muito a desejar e faltam computadores e acesso à rede. Os professores enfatizam o ensino voltado para a preparação para os exames seletivos. Falta incentivo à inovação dos professores por conta na natureza do currículo e do processo de exames de seleção. Estudos da educação na Índia apontam que os estudantes até o primário superior têm interesse em ciências, mas o perdem por conta de um ensino muito tradicional e com um aumento exagerado de dificuldade de um nível a outro (Baxi, 2010).

\section{Brasil}

\section{Panorama geral da educação no Brasil}

A estrutura básica do Sistema Educacional no Brasil compreende a Pré-escola (antes dos 6 anos), Ensino Fundamental I (6-10 anos), Fundamental II (11-14 anos), Ensino Médio (15-17 anos). Atualmente a Química aparece mais formalmente nos dois últimos anos do Ensino Fundamental II e se estende por todo o Ensino Médio. Durante o Ensino Médio há a possibilidade de realizar um ensino profissional concomitante. Há também a Educação de Jovens e Adultos (EJA) para aqueles que não tiveram oportunidade de estudar no tempo adequado e que ocorre geralmente no período noturno. As escolas de maneira geral funcionam em três turnos, manhã ( 7h00-12h30), tarde ( 13h00-17h30) ou noite ( 19h00-23h00). Assim, o mesmo prédio é utilizado nos três turnos. O número de alunos por classe varia em geral de 35-50 (Corio; Fernandez, 2010). As diretrizes da educação são nacionais e seguem a Lei de Diretrizes e Bases da Educação Nacional (Brasil, 1996). Recentemente foi aprovado um currículo nacional - Base Nacional Comum Curricular - em que a Química foi incorporada ao estudo da área de ciências da natureza. A previsão é que esse currículo esteja em atividade a partir de 2019 nas escolas. A entrada na Universidade se dá por um exame seletivo feito ao final do Ensino Médio (Exame Nacional do Ensino Médio, Enem, e outros exames específicos para ingresso em universidades estaduais). Uma contradição importante na educação brasileira é que a maioria dos alunos estuda em escolas públicas ( $90 \%)$ durante a educação básica e somente a elite estuda em escolas particulares que são consideradas em geral de melhor qualidade. Entretanto, no Ensino Superior a situação se inverte, no sentido que as universidades públicas são consideradas as melhores. A contradição está em que os alunos da elite, que puderam pagar por um ensino de maior qualidade durante a educação básica são os que, em geral, conseguem ser selecionados para estudar nas universidades públicas (Fernandez, 2012). Várias iniciativas têm sido feitas para melhorar essa situação (uso de cotas e/ou bônus para alunos de escolas públicas) sem, no entanto, dar conta do problema principal que é a baixa qualidade da educação básica nas escolas públicas. Nos últimos anos houve uma expansão significativa do número de estudantes no Ensino Médio sem a devida expansão na formação de professores. Soma-se a isso o fato de a carreira de professor não ser atrativa no Brasil e, assim, muitos licenciados acabam por seguir 
outras carreiras depois de formados em busca de melhores condições salariais. Segundo um grupo de estudos da Educação Básica pública brasileira:

[...] a efetiva falta de professores em algumas áreas está diretamente relacionada às condições de trabalho usualmente oferecidas; eis o problema real a ser enfrentado. Mantidas tais condições, não adianta muito ofertar oportunidades de melhoria na formação: quanto mais bem preparado se torna um professor, mais ele se afasta da sala de aula da escola básica, buscando trabalho em outros espaços. (Machado, 2018, p.3)

As escolas públicas enfrentam também muitos problemas de infraestrutura. Há falta de itens básicos como bibliotecas e laboratórios em muitas escolas. Os prédios não têm manutenção e a merenda nem sempre é de qualidade. Muitos alunos necessitam viajar por horas até chegarem à escola mais próxima e normalmente não há transporte escolar. Por outro lado, há um Programa Nacional de Livros Didáticos coordenado pelo Ministério da Educação que distribui aos alunos das escolas públicas livros gratuitamente de todas as disciplinas. Os livros são avaliados a cada três anos por equipes de especialistas. Esse é um dos raros programas de sucesso na educação brasileira.

\section{Formação de professores de Química no Brasil}

A expansão do número de alunos no Ensino Médio não foi acompanhada do aumento no número de professores e a carreira de professor no Brasil não é valorizada. Há muitos problemas salariais além de condições estruturais ruins nas escolas. O professor que há aproximadamente 40 anos era valorizado, hoje perdeu seu status social. Muitos trabalham em até três escolas para conseguir sobreviver. Assim há muito pouca atratividade para a carreira de professor, especialmente nas disciplinas de química, física e matemática, onde há falta desses professores.

Hoje em dia a formação de professores se dá em cursos superiores, nas Universidades e nos Institutos Federais. Há também muitos cursos de Licenciatura no formato EaD. Para ser professor no Ensino Fundamental I e primeiros anos do Fundamental II é necessário cursar a Pedagogia, enquanto para atuar nos últimos anos do Ensino Fundamental II e no Ensino Médio é necessário o curso de Licenciatura (no caso, Licenciatura em Química) feito tanto em universidades públicas, particulares, institutos federais ou cursos a distância. Essa determinação de ter um curso universitário para ser professor é bastante recente. As qualidades dos cursos são muito distintas dependendo da instituição que oferece o curso. As disciplinas que compõem os cursos de formação de professores de Química (licenciatura em Química) são um conjunto de disciplinas de Química e outro de disciplinas pedagógicas. Algumas instituições oferecem disciplinas integradoras que congregam conteúdos químicos e pedagógicos. Há também a exigência de 400 h de estágios supervisionados de modo que os licenciandos possam ter contato com a realidade das escolas. Na teoria esse currículo não parece ruim, mas a prática revela uma série de problemas subjacentes. Os 
estágios, por exemplo, apresentam os alunos a uma realidade de escola que assusta mais que ensina. Vários professores em serviço se sentem de alguma forma ameaçados pelos estagiários pela baixa qualidade de ensino que receberam, e muitas vezes são os licenciandos que levam soluções para a escola e não a escola que serve como um local de aprendizado. Para citar uma atividade comum que é oferecida aos estagiários é a reativação do laboratório de Química. Muitas escolas têm laboratório, mas que não é utilizado por não estar organizado, por servir como depósito da escola ou por ter um conjunto de reagentes vencidos. Nessa situação aos licenciandos é dada a tarefa de limpar e organizar o laboratório ao invés de planejar e ministrar aulas. Soma-se a isso o fato de vários docentes da universidade, responsáveis pela disciplina de estágio, nunca terem pisado uma escola real da educação básica e nem terem a licenciatura como formação. O estágio dessa forma fica pouco efetivo e deixa de cumprir sua função principal que é a de fornecer aos licenciandos uma experiência real, numa escola que funciona, e bem orientada.

O currículo da Licenciatura possui ainda um caráter complementar ao curso de Bacharelado, num modelo que ficou conhecido com $3+1$ em que os futuros professores estudam Química durante três anos e um ano de estudos pedagógicos. A junção desses dois mundos não costuma acontecer na universidade, mas somente quando o aluno chega na realidade da escola.

A legislação brasileira não deixa claro quais conhecimentos são essenciais a um professor de Química. Prova disso é o resultado de uma pesquisa de mestrado onde foram analisadas as questões de 60 concursos públicos de seleção de professores de Química de 2003 a 2013 em cinco regiões brasileiras (Figura 1). $\mathrm{O}$ intuito da pesquisa era investigar quais conhecimentos têm sido considerados relevantes para contratar professores de Química para a escola pública básica (Figura 2). Foram analisadas 3576 questões objetivas e 39 questões discursivas (Andrade; Fernandez, 2017).

Observa-se que o Conhecimento do Conteúdo Químico é o mais frequente nas questões de concursos, e o Conhecimento Pedagógico é o segundo conhecimento mais abordado. Por outro lado, o Conhecimento Pedagógico do Conteúdo que é considerado o conhecimento profissional de professores (Fernandez, 2014a,b, 2015) é o menos abordado nos concursos públicos de seleção de professores de Química brasileiros. Na literatura se aponta de há muito tempo a importância de tornar explícito os conhecimentos de professores tanto na formação inicial como na continuada e, por consequência, em exames de seleção de professores (Aydin; Demirdögen, 2015). Assim, pelos resultados obtidos na análise das questões de concursos públicos de seleção de professores de Química, esses professores precisam saber Química, mas não precisam saber ensinar Química. 


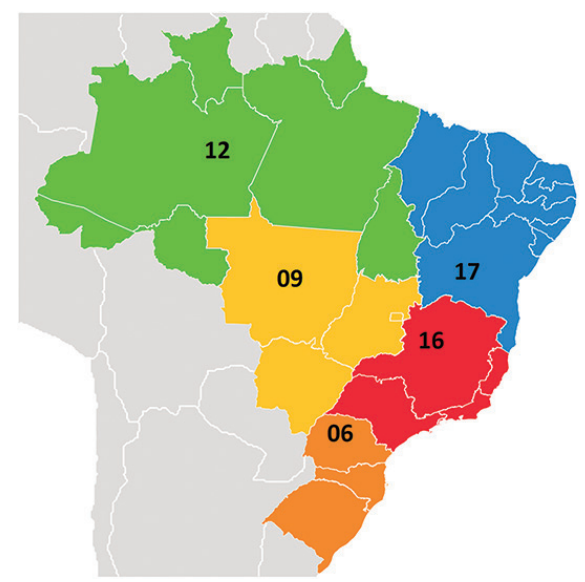

Figura 1 - Número de concursos públicos brasileiros para professores de Química analisados nas diferentes regiões.

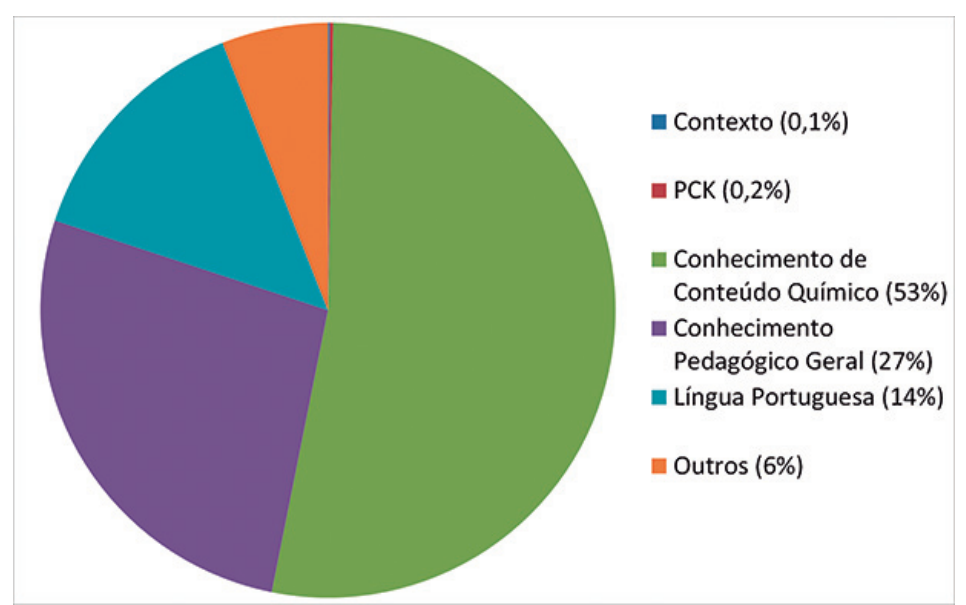

Figura 2 - Conhecimentos abordados nas questões de concursos públicos brasileiros de seleção de professores de Química de 2003 a 2013.

\section{Conclusões}

Ao se descrever a Estrutura Básica dos Sistemas Educacionais nos países apresentados, Alemanha, Austrália, Brasil, Canadá, Estados Unidos, Finlândia e Índia, observam-se muitas similaridades quanto ao número de anos escolares, a divisão nas idades, a presença das Ciências e da Química em particular no currículo. Por outro lado, observam-se grandes diferenças quanto à infraestrutura das escolas na Índia e Brasil em comparação com os demais países, todos de Primeiro Mundo.

A maior diferença, no entanto, ocorre com relação aos professores. Há grandes diferenças entre os países com relação à formação inicial dos professores, à regulamentação e aos requisitos para exercer a profissão, aos conhecimentos necessários para ser professor, à autonomia da atuação dos professores frente 
ao currículo e aos estudantes, e à valorização social da profissão (que se traduz na forma de salários condizentes) e, por consequência o interesse dos jovens em ingressar nessa profissão. Além disso, há grandes disparidades nas condições estruturais das escolas nos distintos países.

Em lugares onde a valorização social dos professores é grande, como Finlândia e Alemanha, há muitos interessados em se tornarem professores e a qualidade desses professores acompanha esse interesse. Por outro lado, esses dois países possuem extensões bem menores que os demais apresentados e, assim podem estar tendo um desafio menor comparativamente. Nos demais países, de extensões semelhantes e também com uma diversidade cultural equivalente, os desafios parecem ser bem mais pronunciados e, mesmo países considerados de primeiro mundo não conseguiram ainda apresentar uma educação de excelência em todos os níveis. Nesses casos parece que uma maior regulamentação da profissão e um acompanhamento mais de perto dos professores e de suas ações em salas de aula - com certificações para atuação que necessitem de atualização de tempos em tempos - tem promovido um maior sucesso em pouco tempo, como foi o caso de Ontário no Canadá e na Austrália. Estados Unidos estão caminhando nessa mesma direção, embora não tenham conseguido ainda fazer que seus estudantes tenham desempenho semelhante. Nos casos de Índia e Brasil há muitos problemas básicos ainda a resolver. Iniciando pela estrutura física das escolas e disponibilidade de materiais curriculares passando pela formação de professores. A formação nesses dois países é pouco regulada, faltam professores de maneira geral e mais ainda de maneira qualificada. A profissão não atrai jovens talentosos e a sociedade não valoriza quem quer seguir na profissão - tanto economicamente como socialmente. Essas condições aproximam países emergentes e pobres. $\mathrm{O}$ ensino é propedêutico, tentando garantir o futuro promissor de apenas alguns e os professores participam dessa engrenagem perversa treinando os alunos para exames seletivos. A Química nesses lugares fica cada vez mais distante dos estudantes e acaba servindo apenas com um dos trampolins para uma vida melhor para poucos estudantes, mas sem sentido para nenhum. E, como apresentamos inicialmente, o papel do conhecimento químico como base para a inovação, alfabetização científica e a solução de problemas em conexão com o desenvolvimento sustentável se perde nos países onde ele seria mais necessário.

Agradecimentos - A autora agradece à Fundação de Amparo à Pesquisa do Estado de São Paulo (Fapesp) o auxílio à pesquisa (Cepid Redoxoma, processo n.2013/079378), ao Conselho Nacional de Desenvolvimento Científico e Tecnológico (CNPq) o auxílio à pesquisa (Universal, processo n.431016/2016-0) e a concessão de bolsa de produtividade em pesquisa (processo n.311879/2015-2). 
Referências

ANDRADE, D. A.; FERNANDEZ, C. Knowledge Base for chemistry teachers evaluated in brazilian selection exams. In: E-proceedings for ESERA 2017, Dublin, Irlanda. Disponível em: <https://keynote.conference-services.net/resources/444/5233/pdf/ ESERA2017_0239_paper.pdf>. Acesso em: 13 set. 2018.

AYDIN, S.; DEMIRDÖGEN, B. Using Pedagogocal Content Knowledge in Teacher Education. In: MACIEJOVSKA, I.;BYERS (Eds) A guidebook of good practice for the pre-service training of chemistry teachers. Faculty of Chemistry, Jagiellonian University in Krakow, Krakow, 2015, p.149-74.

BAXI, S. Teaching Chemistry in India. In: RISCH, B. (Org.) Teaching Chemistry around the world. Berlin: Waxmann Verlag GMBH, 2010. v.1, p.111-21.

BRASIL. Ministério da Educação. Lei de Diretrizes e Bases da Educação Nacional: Lei 9.394/96, 1996.

. . Lei n ${ }^{\circ}$. 9.394, de 20 de dezembro de 1996. Estabelece as Diretrizes e Bases da Educação Nacional. Diário Oficial da União, de 23 dez 1996.

CORIO, P.; FERNANDEZ, C. Teaching Chemistry in Brazil. In: RISCH, B. (Org.) Teaching Chemistry around the world. Berlin: Waxmann Verlag GMBH, 2010. v.1, p.45-66.

DARLING-HAMMOND, L.; LIEBERMAN, A. Teacher Education around the world. New York: Routledge, 2012

FERNANDEZ, C. Teaching Chemistry in Brazil: one country, many realities. In: MARKIC, S. et al. (Org.) Issues of Heterogeneity and Cultural Diversity in Science Education and Science Education Research. Aachen: Shaker Verlag, 2012. v.1, p.107-19.

A base de conbecimentos para o ensino e o Conbecimento Pedagógico do Conteúdo (PCK) de professores de Química. São Paulo, 2014. Tese (Livre-Docência) - Universidade de São Paulo. São Paulo, 2014a.

Knowledge base for teaching and Pedagogical Content Knowledge (PCK): some useful models and implications for teachers'training. Problems of Education in the Twenty First Century, v.60, p.79-100, 2014b.

Revisitando a Base de Conhecimentos e o Conhecimento Pedagógico do Conteúdo (PCK) de professores de ciências. Ensaio: Pesquisa em Educação em Ciências, v.17, p.500-28, 2015.

KIND, V. Pedagogical content knowledge in science education: perspectives and potential for progress. Studies in Science Education, v.45, n.2, p.169-204, 2009.

LAMPISELKÄ., J. Teaching Chemistry in Finland. In: RISCH, B. (Org.) Teaching Chemistry around the world. Berlin: Waxmann Verlag GMBH, 2010. v.1, p.242-66.

LEVIN, B. Building capacity for sustained school improvement. In: DARLING-HAMMOND, L.; LIEBERMAN, A. Teacher Education around the world. New York: Routledge, 2012. p.98-109.

MACHADO, N.J. (coord.) Grupo de Estudos da Educação Básica Pública Brasileira: Dificuldades Aparentes, Desafios Reais. Diagnósticos e Propostas para a Educação Básica Brasileira. Instituto de Estudos Avançados da USP, 2018. 
Disponível em: http://www.iea.usp.br/publicacoes/textos/diagnosticos-e-propostas-para-a-educacao-basica-brasileira Acesso em 25 set. 2018.

MACIEJOVSKA, I.;BYERS, B. Introduction. In MACIEJOVSKA, I.;BYERS (Eds.) A guidebook of good practice for the pre-service training of chemistry teachers. Faculty of Chemistry, Jagiellonian University in Krakow, Krakow, 2015. MASETTO, M. Professor universitários: um profissional da educação na atividade docente. In: . (Org.) Docência na Universidade. 10.ed. Campinas: Papirus, 1998.

OCT Ontario College of Teachers. Disponível em: <https://www.oct.ca/>. Acesso em: 21 set. 2018.

PÉREZ GÓMEZ, A. I. P. As funções sociais da escola: da reprodução à reconstrução crítica do conhecimento e da experiência. In: SACRISTÁN, J. M.; PÉREZ GÓMEZ, A. I. Compreender e transformar o ensino. São Paulo: Artmed, 2000.

RISCH, B. Teaching Chemistry in Germany. In: RISCH, B. (Org.) Teaching Chemistry around the world. Berlin: Waxmann Verlag GMBH, 2010. v.1, p.267-79.

. (Org.) Teaching Chemistry around the world. Münster; New York; München; Berlin: Waxmann Verlag GMBH, 2010.

SAHLBERG, P. The most wanted. Teachers and teacher education in Finland. In: DARLING-HAMMOND, L.; LIEBERMAN, A. Teacher Education around the world. New York: Routledge, 2012. p.1-21.

SAIT, D. India at a crossroads, 2015. Disponível em: <https://eic.rsc.org/opinion/ india-at-a-crossroads /2000410.article>. Acesso em: 21 set. 2018.

SCANTLEBURY, K. Teaching Chemistry in United States of America. In: RISCH, B. (Org.) Teaching Chemistry around the world. Berlin: Waxmann Verlag GMBH, 2010. v.1, p.82-9.

SHULMAN, L. S. Those who understand: knowledge growth in teaching. Educational Researcher, v.15, n.4, p.4-14, 1986.

Knowledge and teaching: foundations of the new reform. Harvard Educational Review, v.57, n.1, p.1-22, 1987.

SILVA, C. P. As contribuições canadenses bem sucedidas para o processo educacional brasileiro. Revista Direito em Ação, Brasília, v.15, n.2, p.50-63, 2015.

TREAGUST, D. F.; CHANDRASEGARAN, A. I. Teaching Chemistry in Australia. In: RISCH, B. (Org.) Teaching Chemistry around the world. Berlin: Waxmann Verlag GMBH, 2010. v.1, p.197-207.

RESUMO - O texto apresenta um panorama do ensino de Química em vários países, e particularmente foca na formação de professores de Química nesses distintos contextos. Nesse sentido, é apresentada a estrutura básica do sistema educacional dos diferentes países, particularidades da escola como horários de funcionamento e número de alunos por classe etc. Em relação à formação de professores de Química descreve-se em linhas gerais como é feita em cada país em termos de currículo além de aspectos práticos da profissão como valorização social e em que tipo de instituição é feita a formação. Foram tratados os seguintes países: Alemanha, Austrália, Brasil, Canadá, Estados Unidos, 
Finlândia e Índia. Há muitas diferenças, mas uma coisa comum entre os países com melhores resultados nas avaliações internacionais recai na atenção e acompanhamento próximo em relação à qualidade da formação de professores, a valorização social e as condições de trabalho nas escolas.

PALAVRAS-CHAVE: Ensino de Química, Formação de professores de Química, Conhecimento de professores de Química.

ABSTRACT - This text presents a panorama of Chemistry Education in several countries and focuses particularly on the training of Chemistry teachers in these different contexts. In this sense, the basic structure of the educational system of different countries is presented, as well as the particularities of the schools, such as working hours, number of students per class etc. The training of Chemistry teachers in each country is described in general terms and in terms of the curriculum, in addition to practical aspects of the profession, such as social valuation and the type of institution in which the training is done. The following countries were appraised: Australia, Brazil, Canada, Finland, Germany, India and United States. There are many differences between them, but some thingg in common in the best-performing countries in international assessments are close attention to, and monitoring of, the quality of teacher education, the social value of teachers and the working conditions in schools.

KErWORDS: Chemistry teaching, Chemistry teachers education, Chemistry teachers' knowledge.

Carmen Fernandez é mestre e doutora em Química e livre-docente na área de Ensino de Química pela Universidade de São Paulo; professora associada do Departamento de Química Fundamental do Instituto de Química da Universidade de São Paulo.

@ - carmen@iq.usp.br

Recebido em 24.9.2018 e aceito em 26.10.2018.

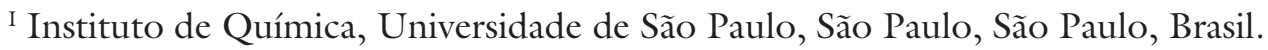

